\title{
SSSPP Position paper: Mental health in competitive sport
}

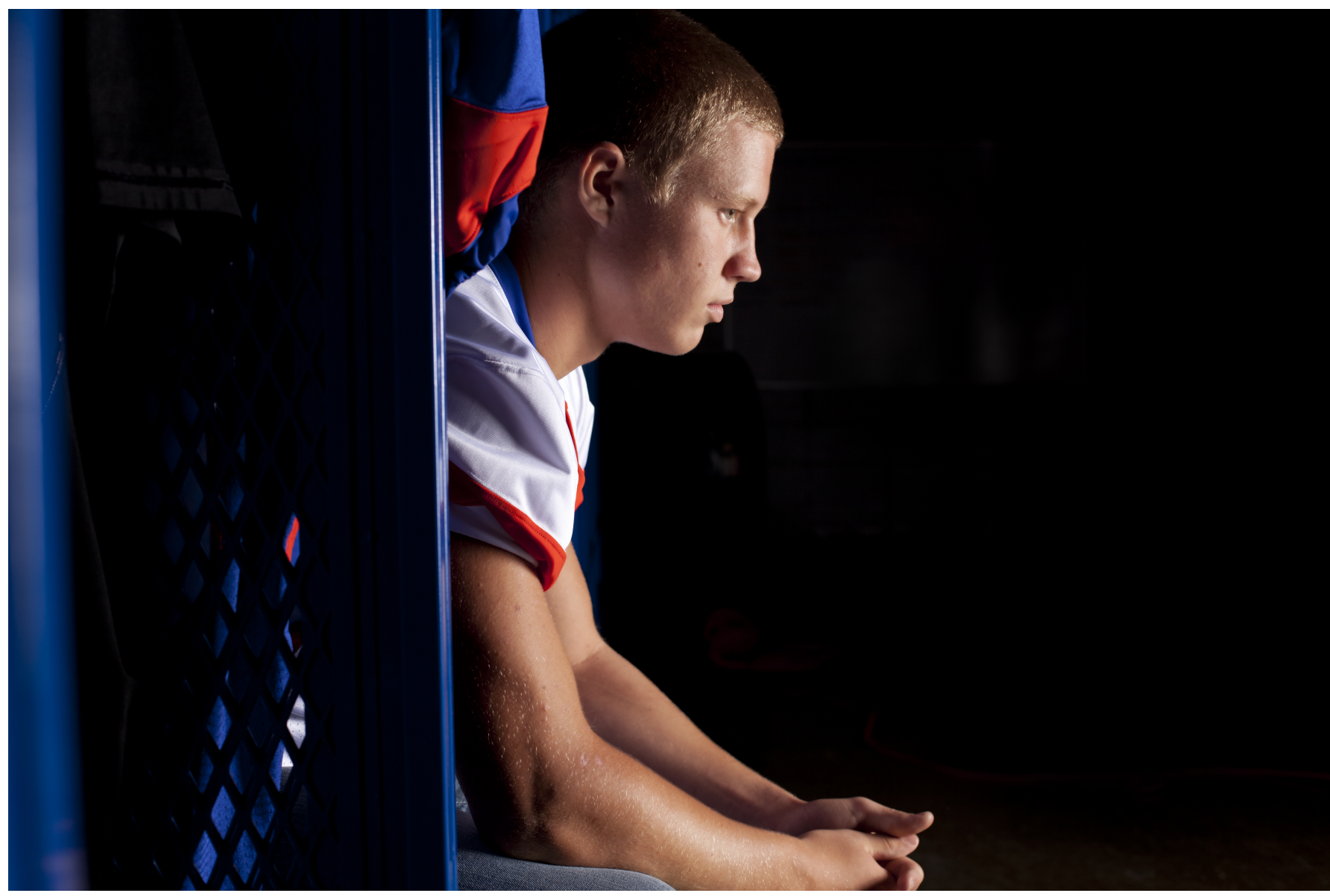

by Swiss Society for Sports Psychiatry and Psychotherapy SSSPP

Claussen Malte Christian ${ }^{1^{*}}$, Gonzalez Hofmann Carlos $^{2^{*}}$, Imboden Christian ${ }^{3}$, Seifritz Erich ${ }^{4}$, Hemmeter Ulrich ${ }^{5}$

${ }^{1}$ Department of Psychiatry, Psychotherapy and Psychosomatics, University Hospital of Psychiatry Zurich, Zurich, Switzerland, Private Clinic Wyss AG, Münchenbuchsee, Switzerland and Psychiatric Services Grisons, Chur, Switzerland

${ }^{2}$ Practice for Psychiatry and Psychotherapy, Romanshorn, Switzerland

${ }^{3}$ Private Clinic Wyss AG, Münchenbuchsee 
${ }^{4}$ Department of Psychiatry, Psychotherapy and Psychosomatics, University Hospital of Psychiatry Zurich

${ }^{5}$ Department for Geriatric Psychiatry and Psychotherapy, Psychiatry St. Gallen North, Wil, Switzerland

\section{* Shared autorship}

\section{Abstract}

Mental disorders are common in competitive sports. They can influence performance, increase the risk of physical injuries and prolong rehabilitation. A specialized discipline for mental health has not (yet) been established. This position paper will emphasize the connection between the special requirements in competitive sports and the need of psychiatric specialization. Approaches for an improving psychiatric and psychotherapeutic care in competitive sports by establishing sports psychiatry and psychotherapy (incl. child and adolescent psychiatry and psychotherapy) as a professional and specialized discipline for mental health are discussed: The qualification of specialists in sports psychiatry and psychotherapy; cooperation in regard to contents and practicality between sports physicians, psychiatrists and psychotherapists and other medical disciplines as well as psychological psychotherapists, sports psychologists, mental coaches and other professions; the inclusion of athletes and parents, other members of the personal psychosocial environment, counsellors as well as clubs and associations.

\section{Zusammenfassung}

Psychische Störungen sind häufig im Leistungssport. Sie können die Leistungsfähigkeit beeinflussen, das Risiko für Verletzungen erhöhen und die Rehabilitation verzögern. Eine spezialisierte Disziplin für psychische Gesundheit im Leistungssport ist (noch) nicht etabliert. Dieses Positionspapier hebt den Zusammenhang zwischen den besonderen Anforderungen im Leistungssport und die Notwendigkeit der psychiatrischen Spezialisierung hervor. Ansätze für die Verbesserung der psychiatrischen und psychotherapeutischen Versorgung im Leistungssport durch die Etablierung der Sportpsychiatrie und psychotherapie (inkl. Kindes- und Jugendpsychiatrie und -psychotherapie) als eine professionelle und spezialisierte Disziplin für psychische Gesundheit werden diskutiert: Die Qualifikation von Spezialisten in Sportpsychiatrie und -psychotherapie; Kooperation bezüglich Inhalt und Praxis mit Sportmedizinern, Psychiatern und -psychotherapeuten und anderen medizinischen Disziplinen sowie mit psychologischen Psychotherapeuten, Sportpsychologen, Mentaltrainer und anderen Professionen; die Einbeziehung von Athleten und Eltern, anderen Personen des psychosozialen Umfelds, Berater sowie Vereine und Verbände.

Mental and social stress is - just like physical stress - an integral part of competitive sports. In the current health care model experts for physical health [sports physicians without postgraduate education in psychiatric specialties and priorities] or specialist disciplines deal with the maintenance of physical health in competitive sports. A specialized discipline for mental health, i.e. for sport psychiatric and psychotherapeutic issues by qualified specialists for psychiatry and psychotherapy and specialists for child and adolescent psychiatry and psychotherapy [sport psychiatrists and psychotherapists] has not (yet) been established for competitive sports. Mental components in competitive sports have so far been addressed by methods that promote the enhancement of performance, resilience, and mental factors, in well-developed 
concepts in sports psychology and mental coaching.

\section{Background}

Mental disorders are common in competitive sports. They can manifest themselves in a sport-specific manner and lead to reduced performance [Mental health in elite athletes: International Olympic Committee consensus statement; (1)]. As in the general population, mental and physical health cannot be considered independently of each other in elite athletes, as mental well-being and physical performance are mutually dependent [1]. Mental disorders in sports can influence performance, increase the risk of physical injuries and prolong rehabilitation. Injuries (can) in turn have an impact on performance and constitute burdens and risks for mental health. Psychological stress and disorders which are unrecognized or not adequately considered in competitive athletes can - as with non-athletes - lead to serious health problems and ultimately existential consequences.

In competitive sports a reliable assessment of the stress and the risk to develop mental disorders are required (concerning prevention), as well as exact diagnosis, therapy and aftercare considering the factors related to competitive sports. Psychiatry and psychotherapy and child and adolescent psychiatry and psychotherapy are the only specialist disciplines that can fully meet these requirements in the framework of a bio-psycho-social model of mental disorders. Sports psychiatry and psychotherapy, as a specialised discipline for mental health, aims to support the current health-promoting measures and efforts to improve mental health in competitive sports.

Other topics of the SSSPP are mental health in popular/mass sports and the promotion of physical activity and sport in the prevention and therapy of mental disorders. In order to promote awareness of the importance of mental health in competitive sports in Switzerland, the Swiss Society for Sports Psychiatry and Psychotherapy SSSPP, was founded on March 29, 2019 (see box).

\section{The purpose of the SSSPP is to promote sports psychiatry and psychotherapy over the lifespan in Switzerland, in competitive sports and in the general population. There- fore, the following two areas of activity will be addressed: 1. Mental health in competitive sports; 2 . Physical activity in the prevention and therapy of mental disorders. Further information on the activities of the SGSPP can be found at: www.sgspp.ch}

For a long time, psychiatry and psychotherapy has not payed adequate attention to mental health in competitive sports. This is particularly evident given the paucity of sports psychiatric and psychotherapeutic care options available for competitive athletes in clinics and medical practices. In 
addition, this is reflected by the lack of structured, specialized postgraduate education and networks regarding sports psychiatry and psychotherapy.

\section{Problematic areas}

In competitive sports there are further aspects of mental health that need to be considered: 
Psychological stress and mental disorders in competitive sports are stıll stıgmatized, despite reports from athletes -some of whom are very prominent- about their psychological burden, during and after their athletic career.

This stigmatization is at least partly due to insufficient awareness and/or a lack of knowledge of the psychological stressors in competitive sports and/or the empirically justified handling of these risks for mental health.

Mental strength and mental health in competitive sports are not the same and are to be differentiated.

The demarcation line between issues typical of competitive sports not requiring treatment and mental disorders - such as between competition anxiety and distinct anxiety disorders - is blurred.

The same lack of demarcation applies to counselling and coaching in relation to psychotherapy. This creates tension between inadequate or insufficient care on the one hand and the risk of psychiatrization of issues that do not necessarily need treatment on the other.

Adolescents are especially prone to mental problems arising from competitive sports. Numerous stress-factors are subject to change in the course of adolescence. Therefore, the participation of child and adolescent psychiatrists and psychotherapists as well as psychiatrists and psychotherapists is essential. Cooperation models have to be developed for the transition phases from adolescence to adulthood, including change of therapists (based on their area of expertise).

Specific, sport-related psychological stress and risk factors have to be taken into account when planning treatments, just as the general sport-specific, psychological requirements and risks.

Regardless of the context of competitive sports mental disorders can also occur in competitive athletes and require evidence-based treatment according to treatmentguidelines.

Prevention is - like diagnosis and therapy - a genuine medical activity that pervades all aspects of medical practice. Therefore, the maintenance of mental health in competitive sports is of central importance for all involved, including the athlete, the parents and the wider psychosocial environment, as well as the clubs and associations in a svstemic wav

Sport psychiatry and psychotherapy and related disciplines

In the context of mental health, the various professional helpers for competitive athletes [including sports physicians, sports psychologists, mental coaches, psychological psychotherapists] each have a different professional background, a different perspective and, in some cases, a different mandate for the athletes. It is important that these different specialists have solid qualifications and competencies to treat mental 
stress and disorders and that they work empirically oriented.

A specialized discipline is required to deal with mental health related stress and risks in competitive sports as well as for professional diagnosis, therapy and aftercare of mental disorders. The basic requirements for such a discipline [sports psychiatrists and psychotherapists] emanate from the special needs experienced by elite athletes with high stress-levels or mental disorders. To meet these requirements, after studying medicine, several years of postgraduate training in psychiatry and psychotherapy, in one of the psychiatric specialties psychiatry and psychotherapy and/or child and adolescent psychiatry and psychotherapy, optimally with additional advanced psychosomatic and further neurological continued education is required.

The additional required specific knowledge and skills in sport psychiatry and psychotherapy have to be acquired in turn to enhance the basic requirements mentioned above.

The boundaries between sports psychiatry and psychotherapy and the above-mentioned disciplines are fluent in some aspects. Likewise, different contractual relationships may exist encompassing the level of the individual, the club and/or the association. This can create difficult and complex situations - e.g. restricted or waived obligations to maintain confidentiality, which can result in areas of tension. It is therefore necessary to establish an interprofessional exchange as well as a cooperation in education and practice in order to provide specific skills of the various experts to the athletes and to achieve the highest level of expertise and transparency.

\section{Approaches}

The Swiss Society for Sports Psychiatry and Psychotherapy is committed to improve psychiatric and psychotherapeutic care in competitive sports by establishing sports psychiatry and psychotherapy as a professional and specialized discipline for mental health. This commitment also reaches beyond the active athletic career and it also applies to coaches and referees.

The envisaged approaches are the following: 
I he qualıtıcation of specialısts in psychiatry and psychotherapy or child and adolescent psychiatry and psychotherapy reflected by a fundamental and certified expertise in sports psychiatry and psychotherapy with a qualification certificate [Curriculum Sports Psychiatry and Psychotherapy. [2]

A close cooperation in regard to contents and topics as well as to practice between all involved disciplines, sports physicians, psychiatrists and psychotherapists, child and adolescent psychiatrists and psychotherapists and other disciplines such as psychological psychotherapists, sports psychologists, mental coaches and other professions.

The inclusion of athletes and parents, other members of the personal psychosocial environment. counsellors as well as clubs and associations.

\section{Recommendations}

The improvement of psychiatric and psychotherapeutic expertise regarding competitive sports will be guaranteed by establishing a specialist discipline for mental health [sports psychiatry and psychotherapy]. Within medicine the quality will be guaranteed by postgraduate education and continuing education in sports psychiatry and psychotherapy [2]. Additionally, the promotion of the content and themes of sports psychiatry and psychotherapy in basic training, postgraduate education and continuing education of medical and non-medical specialties and disciplines should contribute to the improvement. In addition, a continuous interprofessional super- and intervision is required to maintain quality. The Swiss Society for Sports Psychiatry and Psychotherapy is ready to make a fundamental contribution. The maintenance of mental health in competitive sports has to be given the same attention as diagnostics and therapy of mental disorders. In order to fortify the necessary measures for maintaining or restoring mental health, appropriate sports psychiatric and psychotherapeutic information and knowledge dissemination in clubs and associations (e.g. in trainer training) should occur.

The establishment of a specialised coordination center for mental health caring about the central issues of sports psychiatry and psychotherapy in clubs and associations is of central importance for the improvement of the current care model regarding competitive sports. This would provide a chance to reduce the stigmatization of psychological stress phenomena and mental disorders in competitive sports and lead to a better care through swifter treatment of the athletes concerned.

The better coordination of the involved disciplines and synergy effects, which have to be achieved, lead to a better care for the athletes. The FMH position paper on inter-professionalism provides the framework for this core concern [3]: "Every opportunity is preceded by a challenge: the gaps between the health professions have to be closed in order that genuine collaboration based on new and increased synergies can arise and the safety of patients is guaranteed. It is important to define the role of everyone involved in a clearly defined ethical framework, considering the respective competencies of the various players in the healthcare system.”

It is important to ensure that healthcare professionals are transparent towards athletes with regard to the contractual relationships and the associated rules on confidentiality.

\section{Corresponding author}


Dr. med. Malte Christian Claussen

Department of Psychiatry

Psychotherapy and Psychosomatics

University Hospital of Psychiatry

Zurich, Zurich, Switzerland

malte.claussen@pukzh.ch

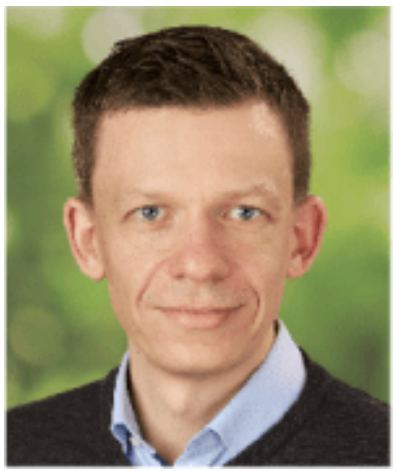

\section{References}

1. Reardon CL, Hainline B, Aron CM, Baron D, Baum AL, Bindra A, et al. Mental health in elite athletes: International Olympic Committee consensus statement (2019). British journal of sports medicine. 2019;53(11):667-99.

2. Claussen MC, Imboden C, Seifritz E, Hemmeter U, Gonzalez Hofmann C. SSSPP Curriculum Sports Psychiatry And Psychotherapy: Level 1. Swiss sports \& exercise medicine. 2020; 68(3):48-52.

3. FMH Zentralvorstand. Die Position des Zentralvorstands der FMH: Interprofessionalität Schweiz Ärzteztg. 2018;99(44):1522-3. 